\title{
Superior oblique tendon expansion in the management of superior oblique dysfunction
}

\author{
M P Clarke, L C Bray, T Manners
}

\begin{abstract}
Traditional superior oblique weakening procedures may be unpredictable and lead to superior oblique underaction. The use of 240 retinal band as a spacer to lengthen the superior oblique tendon has been proposed as a more controlled approach than superior oblique tenotomy and related procedures. The use of this technique is reported in a patient with diplopia following an orbital floor blow out fracture, and in a child with Brown's superior oblique tendon sheath syndrome. (Brf Ophthalmol 1995; 79: 661-663)
\end{abstract}

Superior oblique weakening procedures used in the treatment of superior oblique overaction and Brown's syndrome may be unpredictable. ${ }^{1-4}$ Superior oblique tenotomy is variable in its efficacy and may be complicated by superior oblique paresis and inferior oblique overaction. ${ }^{3-5}$ Patients with fusion may suffer head tilt, vertical or torsional diplopia, or loss of stereopsis following surgery. ${ }^{4}$

To overcome some of these problems, Wright ${ }^{5}$ has developed a new technique for weakening the superior oblique muscle by lengthening the superior oblique tendon using a segment of $2 \mathrm{~mm}$ silicone retinal band. Manners et al have described its use in skew deviation and superior oblique overaction. ${ }^{6}$

We report two cases in which this technique has been successfully employed. The first patient had an orbital blowout fracture, and the second was a child with Brown's superior oblique tendon sheath syndrome.

Accepted for publica 14 February 1995

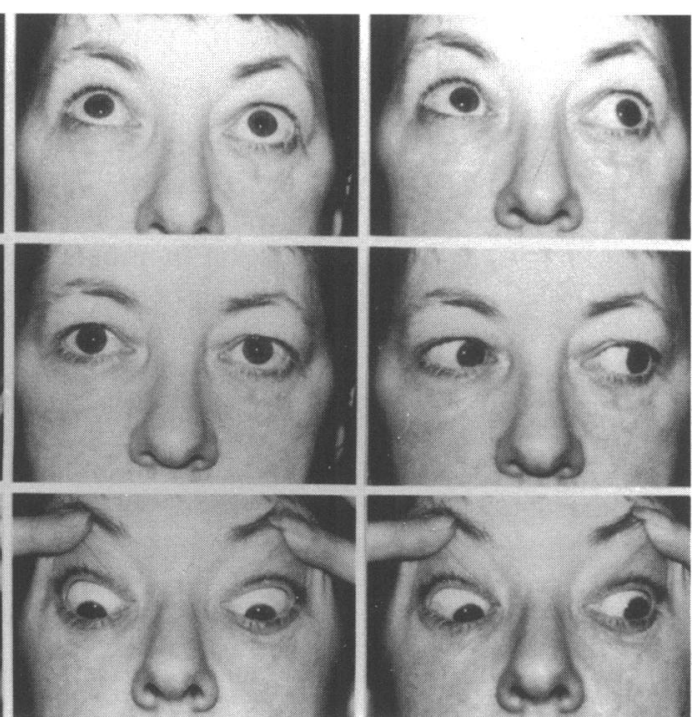

Figure 1 Case 1. Preoperative nine gaze composite photograph. Note the marked right superior oblique overaction.
Versions were quantified using a nine point scoring system ${ }^{7}(-4$ to +4$)$. The amount of $A$ or $\mathrm{V}$ pattern was determined by comparing distance alternate cover test measurements in $20^{\circ}$ upgaze and $20^{\circ}$ downgaze.

\section{Patients and methods}

\section{CASE 1}

A 46-year-old woman was seen in the eye department 2 days after sustaining a left orbital blowout fracture. Initial examination revealed a chin up head posture and restriction of left elevation with a 20 dioptre right hypertropia in the primary position. Two weeks after the injury, there was no improvement in elevation of the left eye, and in addition restriction of depression of the left eye was apparent. A computed tomography (CT) scan demonstrated a large orbital floor fracture, with herniation of orbital contents into the maxillary antrum. The orbital floor was explored 1 month after the injury, entrapped tissue was freed, and the defect repaired with Silastic. There was little change in ocular motility following this procedure, and a subsequent CT scan demonstrated persistent herniation of tissue through the fracture site. A further operation was performed 9 months after the original injury, and a bony defect was found posterior to the limit of the original Silastic sheet which was replaced.

Three months after the second orbital procedure, there was no diplopia in the primary position, but there was limitation of vertical ductions of the left eye with a small field of binocular single vision (Figs 1 and 2). There was a right superior oblique overaction of +3 . A forced duction test showed limitation of upward movement of the left eye, and a force generation test demonstrated inferior rectus function. Diplopia in downgaze was particularly troublesome.

To improve the field of binocular single vision in downgaze, a right superior oblique tendon expansion of $6 \mathrm{~mm}$ was performed. The outcome is discussed in the results section.

CASE 2

A 7-year-old boy was seen in the eye department from the age of 3 years with a right Brown's syndrome. There was a right esotropia of 30 prism dioptres in the primary position and a -4 limitation of elevation in adduction of the right eye (Fig 5, preoperative). There was no spontaneous improvement over the subsequent 4 years, and his 


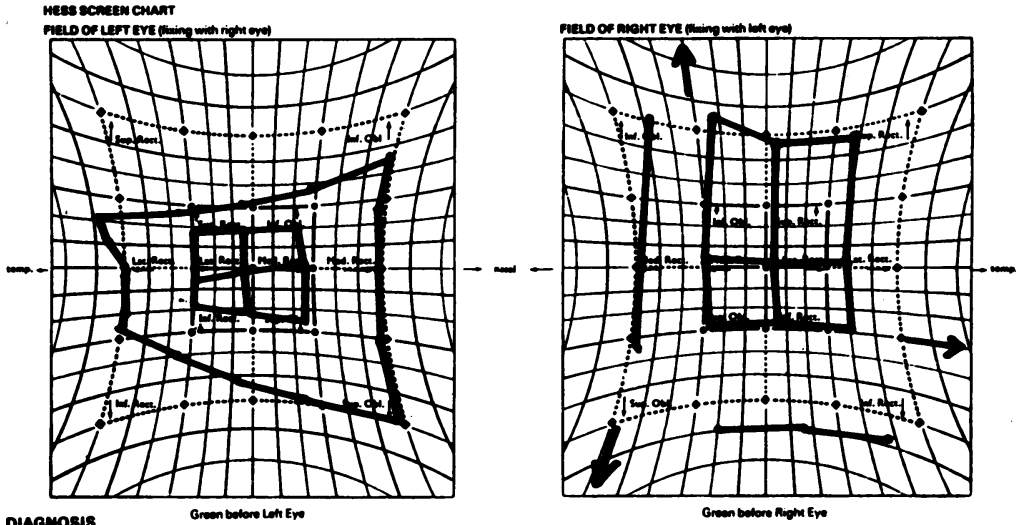

Figure 2 Case 1. Preoperative Hess chart.

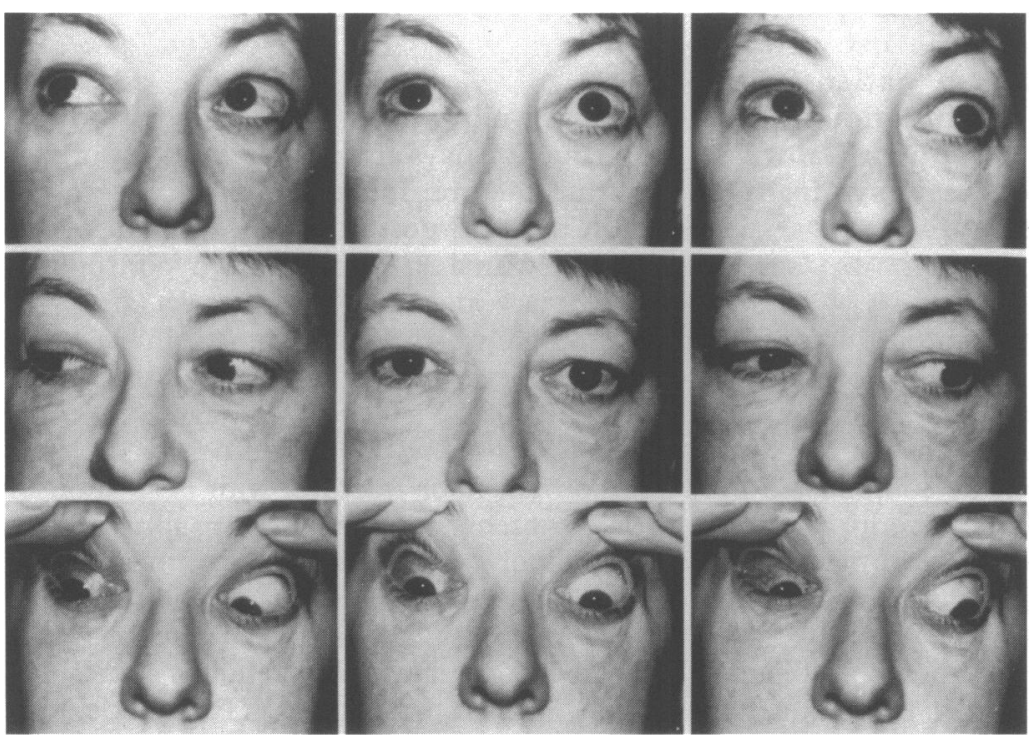

Figure 3 Case 1. Postoperative nine gaze composite photograph taken 10 days after surgery. Note the significant reduction in right superior oblique overaction.
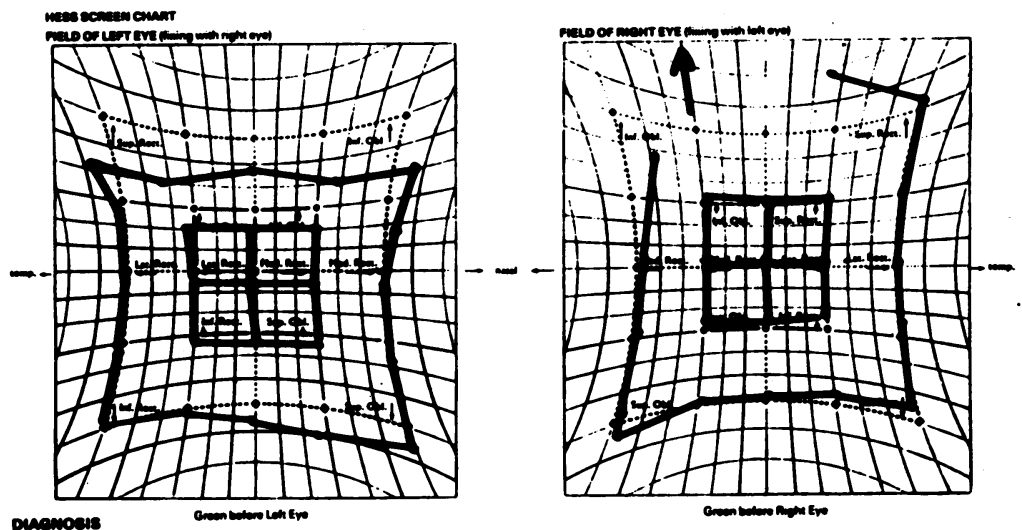

Figure 4 Case 1. Postoperative Hess chart recorded 10 days after surgery.

parents requested surgery because the boy was teased at school about his appearance.

Under general anaesthesia, forced duction testing confirmed the diagnosis of Brown's syndrome. The right superior oblique tendon was lengthened $7 \mathrm{~mm}$ using a 40 retinal detachment band. After this procedure, elevation of the right eye was improved, but the horizontal deviation was increased. At a second procedure, both medial recti were recessed $4 \mathrm{~mm}$.
SURGICAL TECHNIQUE FOR SUPERIOR OBLIQUE TENDON EXPANSION

The surgical technique described by Wright ${ }^{5}$ uses a modified Park's temporal approach ${ }^{8}$ through which the superior oblique muscle is isolated. The tendon is exposed through a small incision in the roof of the superior oblique capsule, while preserving the floor of the capsule. The segment of silicone is sutured between the cut ends of the tendon with double armed 5-0 Mersilene suture placed 2 to $3 \mathrm{~mm}$ nasal to the superior rectus muscle.

The length of silicone expander used was determined by the degree of superior oblique overaction, thus 3 to $4 \mathrm{~mm}$ for $+2,5 \mathrm{~mm}$ for $+2,6 \mathrm{~mm}$ for +3 , and $7 \mathrm{~mm}$ for +4 . A 6 or 7 $\mathrm{mm}$ expander was used in patients with Brown syndrome and intraoperative forced duction tests performed to verify that restriction had been adequately relieved.

\section{Results}

In case 1 , superior oblique overaction was eliminated, resulting in a marked symptomatic improvement and increased comitance. Figure 3 shows the appearance 2 months after surgery, and Figure 4 shows the Hess chart 1 year after superior oblique tendon expansion, and 2 years following the original injury.

The field of binocular single vision was scored for complete, superior, and inferior half fields, using the method described by Woodruff et al. ${ }^{9}$ The complete field score was improved from $66 \%$ preoperatively to $81 \%$ at 6 months after surgery. These overall scores masked the dramatic effect of the surgery on the inferior half field which improved from $67 \%$ preoperatively to $97 \%$ at 6 months after surgery. The scores for superior half fields were $64 \%$ preoperatively and $53 \% 6$ months after surgery. This overall improvement has been maintained over the 2 year follow up.

The marked improvement in cosmetic appearance 1 year after surgery in case 2 is seen when comparing Figures 5 and 6 . There was a small right hypertropia and right esotropia in all gaze positions, but the cosmetic appearance was much improved and considered satisfactory by the parents.

\section{Discussion}

The technique of superior oblique tendon expansion described by Wright allows a graded reduction in superior oblique overaction to be achieved thereby reducing the incidence of postoperative palsy or residual overaction. ${ }^{8}$ The two cases reported illustrate some of the advantages of the technique.

In case 1 , orbital blowout fracture was complicated by diplopia which persisted despite early repair of the orbital floor. Diplopia is likely to have been the result of either direct muscle or nerve damage, or scarring and fixation of previously entrapped tissue. ${ }^{10}$

The surgical options were an inverse Knapp procedure on the affected eye or a contralateral superior oblique weakening procedure. A inverse Knapp procedure may improve both 


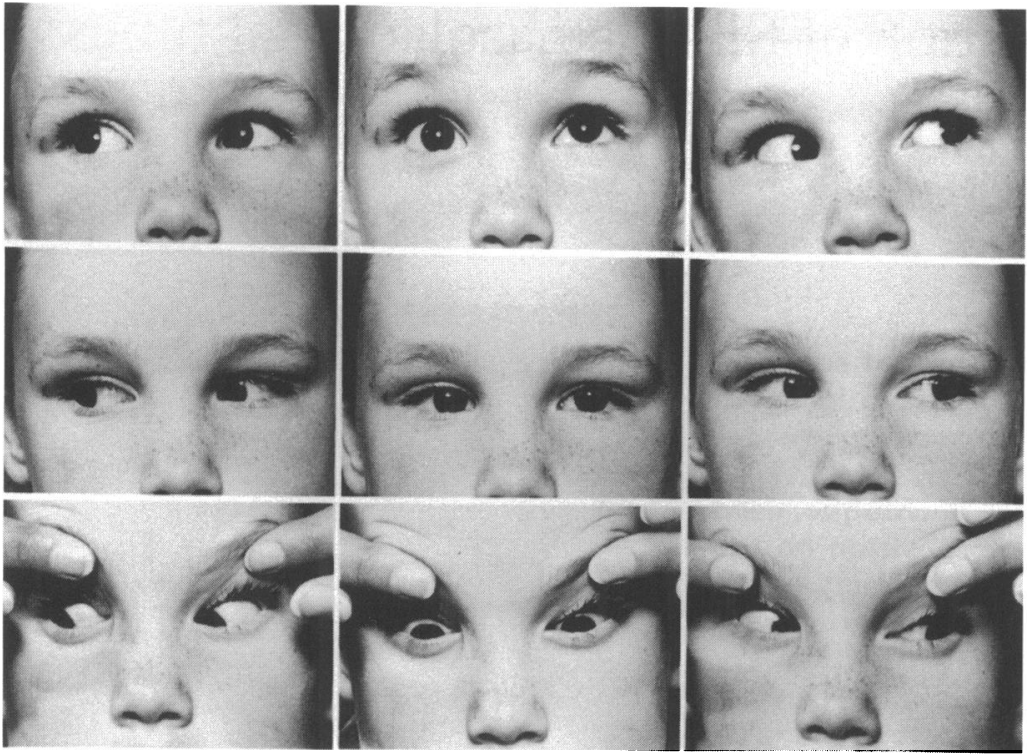

Figure 5 Preoperative eye movements case 2.
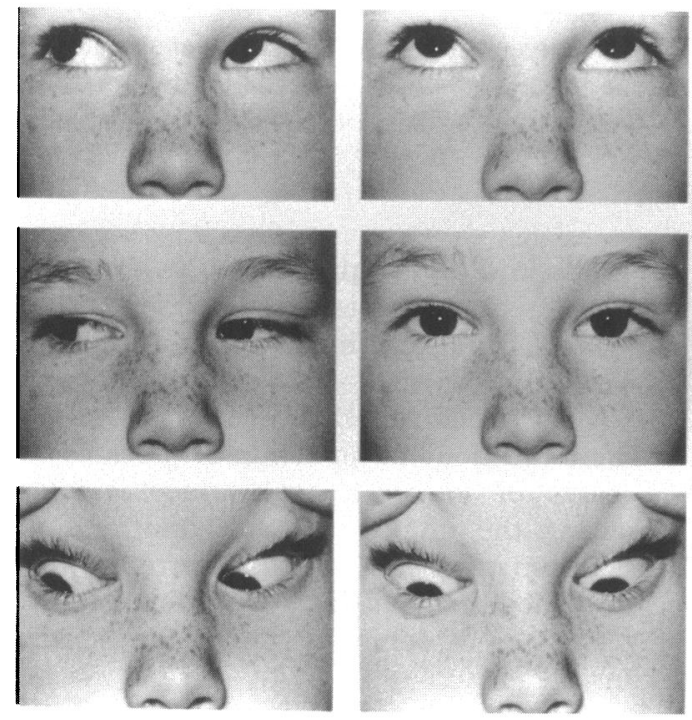

Figure 6 Postoperative eye movements case 2.

superior and inferior fields of binocular single vision in patients with inferior rectus paresis, ${ }^{11}$ but risks aggravating diplopia in the primary position. A weakening procedure on the contralateral superior oblique muscle was felt to be the best method of reducing incomitance in downgaze and as the patient had fusion, the silicone expander procedure was felt to be most appropriate. There was no diplopia due to excyclotorsion postoperatively. We recommend that it is considered as a surgical option in patients with persistent diplopia following inferior orbital wall blowout fractures.

Brown's syndrome often requires no surgical intervention and spontaneous resolution is reported in $10 \%$ of cases. ${ }^{12}$ However, when surgical treatment is required, results are unpredictable. ${ }^{13-15}$ Superior oblique tenotomy is frequently associated with both undercorrection and superior oblique palsy. ${ }^{13} 15$ The incidence of palsy can be reduced by ipsilateral inferior oblique recession but this may further reduced elevation in adduction. ${ }^{15}$ When the silicone expander technique is used, inferior oblique weakening is unnecessary. The good and stable cosmetic result achieved by the use of a silicone expander is matched by reports in the literature. ${ }^{13}$

The authors thank Mrs A Smith for secretarial help.

1 Urist MJ. Complications following bilateral superior oblique weakening surgical procedures for A-pattern horizontal weakening surgical procedures for A-pattern
deviations. $A m \Im$ Ophthalmol 1970; 70: 583-7.

2 Souza-Dias C, Uesugui CF. Efficacy of different techniques of superior oblique weakening in the correction of ' $A$ ' anisotropia. I Pediatr Ophthalmol Strabismus 1986; 23: $82-6$.

3 Scott WE, Jampolsky AJ, Redmond MR. Superior oblique tenotomy: indications and complications. Int Ophthalmol Clin 1976; 16: 151-9.

4 Parks MM. Commentary on superior oblique tenotomy for A-pattern strabismus in patients with fusion. Binocular Vision 1988; 3: 39.

5 Wright KW. Color atlas of ophthalmic surgery: strabismus. Philadelphia: JB Lippincott, 1991: 201-16.

6 Manners RM, O'Flynn E, Morris RJ. Superior oblique tendon lengthening for acquired superior oblique overactions. Br f Ophthalmol 1994; 78: 280-4.

7 Doughty DD, Lennarson LW, Scott WE. A graphic portrayal of versions. Perspect Ophthalmol 1978; 2: 55-9.

8 Parks MM. Atlas of strabismus surgery. Philadelphia: Harper \& Row, 1983: 191 .

9 Woodruff G, O'Reilly C, Kraft SP. Functional scoring of the field of binocular single vision in patients with diplopia. Ophthalmology 1987; 94: 1554-61.

10 Koorneef L. Current concepts on the management of orbital blow-out fractures. Ann Plast Surg 1982; 9: orbital blov.

11 Lipton JR, Page AB, Lee JP. Management of diplopia on downgaze following orbital trauma. Eye 1990; 4: 535-7.

12 Kaban TJ, Smith K, Orton RB, Noel LP, Clarke W, Cadera W. Natural history of presumed congenital Brown syndrome. Arch Ophthalmol 1993; 111: 943-6.

13 Wright KW, Min B-M, Park C. Comparison of superior oblique tendon expander to superior oblique tenotomy for the management of superior oblique overaction and Brown syndrome. $\mathcal{F}$ Pediatr Ophthalmol Strabismus 1992; 2: 92-7.

14 Crawford JS. Surgical treatment of true Brown's syndrome. Am f Ophthalmol 1976; 81: 289-95.

15 Parks MM, Eustis HS. Simultaneous superior oblique tenotomy and inferior oblique recession in Brown's syndrome. Ophthalmology 1987; 94: 1043-8. 